\title{
UJI EFEK PEMBERIAN ASAM MEFENAMAT SEBELUM PENCABUTAN GIGI TERHADAP DURASI AMBANG NYERI SETELAH PENCABUTAN GIGI
}

\author{
${ }^{1}$ Febriana \\ 2 Jimmy Posangi \\ ${ }^{3}$ Bernat S. P. Hutagalung
}

\author{
${ }^{1}$ Kandidat Skripsi Mahasiswa Program Studi Pendidikan Dokter Gigi Fakultas Kedokteran \\ ${ }^{2}$ Bagian Farmakologi dan Terapi Fakultas Kedokteran \\ ${ }^{3}$ Program Studi Pendidikan Dokter Gigi Fakultas Kedokteran \\ Universitas Sam Ratulangi Manado \\ E-mail: yana_basar@yahoo.com
}

\begin{abstract}
The action tooth extraction is one of the medical procedures that makes the patient feel fear and anxiety, the pain felt is one of reason for the patient's fear and anxiety to go to the dentist. Pain is an unpleasant taste and cause suffering and pain. For the reduction of fear and anxiety, operator must perform good preparation before doing tooth extraction or revocation action. Preparations that can be done by operator one of them to overcome pain in patients by administration of analgesic and local anesthesia given. The purpose on this study is to determine the effect of mefenamic acid given before tooth extraction for the duration of the threshold of pain after tooth extraction action.The research method used is a quasi experimental design post test only with control design. The sampling used is purposive sampling based on inclusion and exclusion criteria with a sample of 20 patients, 10 patients as test group were given the drugs and 10 patients with the control were not given the drug was conducted in August-September 2015. The data is processed and analyzed bivariat and presented in the form of a frequency distribution table.Based on the result of research shows after tooth extraction, that the duration of the patient's pain threshold in a given mefenamic acid before tooth extraction longer than with a patient not given mefenamic acid before tooth extraction. The average duration successive is 3 hours 28 minutes and 2 hours 11 minutes, so the difference of duration of 1 hours 17 minutes. Conclusion: Mefenamic acid given before tooth extraction extended the duration of pain threshold after tooth extraction.
\end{abstract}

Keywords: tooth extraction, mefenamic acid, the duration of the pain threshold.

\begin{abstract}
Abstrak: Tindakan pencabutan gigi merupakan salah satu tindakan medis yang membuat pasien merasa takut dan cemas, nyeri yang dirasakan adalah salah satu alasan pasien untuk takut dan cemas pergi ke dokter gigi. Nyeri yaitu rasa yang tidak menyenangkan dan menimbulkan derita serta rasa sakit. Untuk mengurangi rasa takut dan cemas, operator harus melakukan persiapan yang baik sebelum melakukan tindakan pencabutan. Persiapan yang dapat dilakukan oleh operator salah satunya mengatasi nyeri pada pasien yaitu dengan pemberian analgesik dan anastesi lokal. Tujuan dari penelitian ini yaitu untuk mengetahui efek pemberian asam mefenamat sebelum pencabutan gigi terhadap durasi ambang nyeri setelah tindakan pencabutan gigi. Metode penelitian yaitu eksperimental quasi dengan rancangan post test only with control design. Pengambilan sampel yang digunakan yaitu purposive sampling berdasarkan kriteria inklusi dan eksklusi dengan jumlah sampel 20 pasien, 10 pasien sebagai kelompok uji (diberi obat) dan 10 pasien kelompok kontrol (tidak diberi obat) dilakukan pada bulan Agustus-September 2015. Data diolah dan dianalisis secara bivariat dan disajikan dengan distribusi frekuensi dalam bentuk tabel. Hasil penelitian memperlihatkan setelah
\end{abstract}


pencabutan gigi, durasi ambang nyeri pada pasien yang diberikan asam mefenamat sebelum pencabutan gigi lebih lama dibandingkan dengan pasien yang tidak diberikan asam mefenamat sebelum pencabutan gigi. Rata-rata durasi berturut-turut 3 jam 28 menit dan 2 jam 11 menit, jadi selisihnya yaitu 1 jam 17 menit. Simppulan: Pemberian asam mefenamat sebelum pencabutan gigi memperpanjang durasi ambang nyeri setelah pencabutan gigi.

Kata kunci: pencabutan gigi, asam mefenamat, durasi ambang nyeri

Prosedur pencabutan gigi merupakan salah satu dari sekian banyak perawatan gigi yang dilaksanakan di Rumah Sakit Gigi dan Mulut. Tindakan pencabutan gigi merupakan salah satu tindakan medis yang membuat pasien merasa takut dan cemas. Prosedur pencabutan gigi yang menggunakan benda-benda tajam seperti jarum, elevator (bein) dan tang dalam pengaplikasiannya dimasukkan secara berurutan maupun bergantian ke dalam mulut dianggap sebagai hal yang mengerikan dan menjadi pencetus terjadinya kecemasan pasien. Kecemasan dalam praktek dokter gigi merupakan halangan yang sering mempengaruhi perilaku pasien dalam perawatan gigi. Telah diketahui bahwa banyak pasien yang menjadi cemas sebelum dan sesudah perawatan gigi. ${ }^{1}$ Dalam bidang kedokteran gigi, nyeri yang dirasakan adalah salah satu alasan pasien untuk takut dan cemas pergi ke dokter gigi. Nyeri yaitu rasa yang tidak menyenangkan dan menimbulkan derita serta rasa sakit. ${ }^{2}$ Nyeri merupakan sensasi yang paling penting bagi tubuh manusia. Untuk mengurangi rasa takut dan cemas pada pasien, operator harus melakukan persiapan yang baik sebelum melakukan tindakan pencabutan. Persiapan yang dapat dilakukan oleh operator salah satunya mengatasi nyeri pada pasien yaitu dengan pemberian analgesik dan anastesi lokal.

Sebagian besar penyakit yang melibatkan gigi memberikan efek nyeri yang luar biasa. Hal ini disebabkan oleh aktivasi reseptor nyeri pada pulpa gigi oleh rangsangan termal, mekanik, kimia, ataupun elektrik. Untuk mengatasi nyeri pada pasien memerlukan pemberian analgesik baik sebelum pencabutan maupun sesudah pencabutan gigi. Analgesik terbagi menjadi 2 kelompok besar yaitu : analgesik non-narkotika (nonopioid) dan analgesik opioid. ${ }^{3}$

Analgesik non-narkotik yang paling sering digunakan dalam bidang kedokteran gigi adalah asam mefenamat, aspirin, dan parasetamol. Asam mefenamat termasuk dalam golongan obat NSAID (non steroid anti inflammatory drug) yang bekerja sangat baik dalam menangani nyeri. Asam mefenamat juga merupakan salah satu analgesik yang sering digunakan di RSGM oleh mahasiswa kepaniteraan klinik pasca pencabutan gigi.

Pada penelitian sebelumnya sudah pernah dilakukan oleh Naharuddin M pada tahun 2013 di Makasar tentang pemberian premedikasi tramadol sebelum melakukan tindakan pencabutan gigi dengan hasil adanya perbedaan signifikan mengenai durasi ambang nyeri setelah pencabutan gigi pada pasien yang diberi tramadol sebelum pencabutan dibandingkan dengan pasien yang tidak diberi tramadol. Tramadol merupakan salah satu analgesik yang termasuk pada kelompok narkotika (opioid) sedangkan asam mefenamat merupakan analgesik non-narkotik (nonopioid). Peneliti merasa tertarik untuk melihat bagaimana pengaruh pemberian analgesik asam mefenamat sebelum pencabutan gigi dan pengaruhnya terhadap durasi ambang nyeri setelah pencabutan gigi.

\section{METODE PENELITIAN}

Penelitian yang digunakan yaitu eksperimental quasi dengan rancangan post test only with control design di Rumah Sakit Gigi dan Mulut Manado pada bulan Agustus s/d September 2015. Sampel penelitian 20 orang, 10 orang diberi perlakuan asam mefenamat (kelompok uji) dan 10 orang tidak diberi perlakuan 
(kelompok kontrol), berusia 17-55 tahun, gigi yang dicabut adalah gigi anterior dan posterior, tidak menderita riwayat penyakit sistemik dan tidak minum analgesik sebelum datang ke RSGM Manado dengan teknik pengambilan sampel menggunakan purposive sampling. Sebelum menjalani pencabutan gigi kelompok uji akan diberikan analgesik jenis asam mefenamat, setelah 1 jam operator akan melakukan tindakan pencabutan gigi dengan melakukan anestesi lokal terlebih dahulu dengan dosis yang sama untuk gigi anterior dengan teknik infiltrasi $1 / 2$ cc di palatal / lingual dan $1 / 2$ cC di labial. Untuk gigi posterior 1cc untuk anestesi blok alveolus inferior, $1 / 2$ CC untuk nervus lingualis dan $1 / 2$ cc untuk nervus bukalis. Setelah gigi pasien dicabut pasien akan melakukan pengisian skala numerik. Kemudian peneliti juga akan mengisi skala wajah Whaley dan Wong. Untuk kelompok kontrol akan dilakukan hal sama hanya bedanya pada kelompok kontrol tidak diberikan obat sebelum pencabutan gigi. Setelah memperoleh semua data yang diperlukan, data diolah dan disajikan berdasarkan distribusi frekuensi dalam bentuk tabel.

\section{HASIL PENELITIAN}

Tabel 1. Karakteristik subjek penelitian terdiri dari jenis kelamin, diagnosis, kelompok usia dan pemberian analgesik

\begin{tabular}{cccc}
\hline Karakteristik & & $\mathrm{n}$ & $\%$ \\
\hline \multirow{3}{*}{ Jenis Kelamin } & Laki-laki & 6 & 30 \\
& Perempuan & 14 & 70 \\
& Total & 20 & 100 \\
\hline \multirow{3}{*}{ Diagnosis } & Nekrosis pulpa & 16 & 80 \\
& pulpitis Irreversibel & 4 & 20 \\
& Total & 20 & 100 \\
\hline \multirow{3}{*}{ Kelompok Usia } & $17-25$ tahun & 9 & 45 \\
& $26-35$ tahun & 5 & 25 \\
& $36-45$ tahun & 1 & 5 \\
& $46-55$ tahun & 5 & 25 \\
& Total & 20 & 100 \\
\hline \multirow{2}{*}{ Pemberian Analgesik } & Kelompok Uji & 10 & 50 \\
& Kelompok Kontrol & 10 & 50 \\
& Total & 20 & 100 \\
\hline
\end{tabular}

Tabel 2. Nyeri pada pasien kelompok uji dan pasien kelompok kontrol berdasarkan pengukuran Skala Numerik

\begin{tabular}{ccccc}
\hline & \multicolumn{3}{c}{ Pemeriksaan pengukuran Skala Numerik } \\
\cline { 2 - 5 } Kategori & & $\begin{array}{c}\text { Kelompok uji } \\
\%\end{array}$ & Kelompok kontrol \\
& $\mathrm{n}$ & 0 & 0 & $\%$ \\
\hline 0 & 0 & 10 & 0 & 0 \\
1 & 1 & 80 & 1 & 0 \\
2 & 8 & 10 & 7 & 70 \\
3 & 1 & 0 & 2 & 20 \\
4 & 0 & 0 & 0 & 0 \\
5 & 0 & 0 & 0 & 0 \\
6 & 0 & 0 & 0 & 0 \\
7 & 0 & 0 & 0 \\
8 & 0 & 0 & 0 & 0 \\
9 & 0 & 0 & 0 & 0 \\
10 & 0 & 0 & 10 & 100 \\
Total & 10 & 100 & & \\
\hline
\end{tabular}


Febriana, Posangi, Hutagalung: Uji efek pemberian...

Tabel 3. Nyeri pada pasien kelompok uji dan pasien kelompok kontrol berdasarkan pengukuran Skala Wajah Wong-Baker

\begin{tabular}{ccccc}
\hline & \multicolumn{4}{c}{ Pemeriksaan pengukuran skala wajah } \\
\cline { 2 - 5 } Kategori & \multicolumn{4}{c}{ Wong-Baker } \\
\cline { 2 - 5 } & Kelompok uji & \multicolumn{2}{c}{ kontrol } \\
& $\mathrm{n}$ & $\%$ & $\mathrm{n}$ & $\%$ \\
\hline 0 & 0 & 0 & 0 & 0 \\
1 & 4 & 40 & 0 & 0 \\
2 & 6 & 60 & 8 & 80 \\
3 & 0 & 0 & 2 & 20 \\
4 & 0 & 0 & 0 & 0 \\
5 & 0 & 0 & 0 & 0 \\
Total & 10 & 100 & 10 & 100 \\
\hline
\end{tabular}

Tabel 4. Durasi ambang nyeri berdasarkan waktu pemberian asam mefenamat, waktu anestesi dan waktu rasa nyeri yang muncul pada pasien kelompok uji

\begin{tabular}{cccccc}
\hline No & $\begin{array}{c}1 \\
\text { Pemberian } \\
\text { asam } \\
\text { mefenamat } \\
\text { (jam) }\end{array}$ & $\begin{array}{c}2 \\
\text { Pemberian } \\
\text { anestesi } \\
\text { Pehacaine } \\
\text { (jam) }\end{array}$ & $\begin{array}{c}3 \\
\text { Rasa nyeri yang } \\
\text { muncul setelah } \\
\text { pencabutan } \\
\text { (jam) }\end{array}$ & $\begin{array}{c}\text { Durasi ambang } \\
\text { nyeri asam } \\
\text { mefenamat } \\
\text { (jam) }\end{array}$ & $\begin{array}{c}\text { Durasi } \\
\text { ambang } \\
\text { nyeri } \\
\text { anestesi } \\
\text { (jam) }\end{array}$ \\
\hline 1 & 10.00 & 11.00 & 14.00 & 4 & 3 \\
2 & 10.15 & 11.15 & 14.30 & 4,15 & 3.15 \\
3 & 11.00 & 12.00 & 15.30 & 4,30 & 3.30 \\
4 & 10.10 & 11.10 & 14.50 & 4,40 & 3.40 \\
5 & 09.50 & 10.50 & 15.00 & 5,10 & 4.10 \\
6 & 10.00 & 11.00 & 14.15 & 4,15 & 3.15 \\
7 & 10.00 & 11.00 & 14.30 & 4,30 & 3.30 \\
8 & 10.10 & 11.10 & 14.40 & 4,30 & 3.30 \\
9 & 11.00 & 12.00 & 15.00 & 4 & 3 \\
10 & 11.30 & 12.30 & 15.40 & 4,10 & 3.10 \\
\hline \multicolumn{5}{c}{} \\
\hline
\end{tabular}

Tabel 5. Durasi ambang nyeri berdasarkan waktu anestesi dan waktu rasa nyeri yang muncul pada pasien kelompok kontrol

\begin{tabular}{cccc}
\hline No & 1 & $\begin{array}{c}2 \\
\text { Rasa nyeri yang muncul } \\
\text { setelah pencabutan } \\
\text { (jam) }\end{array}$ & $\begin{array}{c}\text { Durasi ambang } \\
\text { nyeri anestesi (jam) }\end{array}$ \\
\hline 11 & 10.50 & 13.00 & 2.10 \\
12 & 11.30 & 13.45 & 2.15 \\
13 & 11.30 & 14.00 & 2.30 \\
14 & 10.20 & 12.30 & 2.10 \\
15 & 10.10 & 12.10 & 2 \\
16 & 11.15 & 13.30 & 2.15 \\
17 & 11.45 & 14.00 & 2.15 \\
18 & 10.00 & 13.50 & 2.50 \\
19 & 10.15 & 12.30 & 2.15 \\
20 & 10.20 & 13.00 & 1.50 \\
\hline
\end{tabular}


Tabel 6. Rata-rata durasi ambang nyeri berdasarkan jenis kelamin, diagnosis dan kelompok usia

\begin{tabular}{cccc}
\hline \multicolumn{2}{c}{ Karakteristik } & $\mathrm{n}$ & $\begin{array}{c}\text { Rata-Rata } \\
\text { durasi ambang } \\
\text { nyeri (jam) }\end{array}$ \\
\hline Jenis Kelamin & Laki-laki & 6 & 3.30 \\
& Perempuan & 14 & 3 \\
\hline Diagnosis & Nekrosis pulpa & 16 & 3.34 \\
& Pulpitis Irreversibel & 4 & 3.02 \\
\hline \multirow{3}{*}{ Kelompok Usia } & $17-25$ tahun & 9 & 3.03 \\
& $26-35$ tahun & 5 & 2.55 \\
& $36-45$ tahun & 1 & 2.10 \\
& $46-55$ tahun & 5 & 2.34 \\
\hline
\end{tabular}

Tabel 7. Selisih durasi ambang nyeri kelompok uji dan kelompok kontrol berdasarkan rata-rata durasi ambang nyeri

\begin{tabular}{cc}
\hline Kelompok Analgesik & Rata-Rata (jam) \\
\hline Kelompok Uji & 3.28 \\
Kelompok Kontrol & 2.11 \\
\hline Selisih & 1.17 \\
\hline
\end{tabular}

\section{BAHASAN}

Pencabutan gigi merupakan suatu tindakan dalam dunia kedokteran gigi yang umumnya menjadi pencetus timbulnya rasa nyeri. Faktor-faktor yang dapat memengaruhi rasa nyeri pada pasien pencabutan gigi yaitu jenis kelamin, usia, keadaan gigi sebelum pencabutan, pemberian analgesik sebelum pencabutan gigi dan anestesi lokal.

Berdasarkan jenis kelamin didapatkan data bahwa rata-rata durasi ambang nyeri lakilaki sebesar 3 jam 30 menit lebih lama dibandingkan dengan perempuan sebesar 3 jam saja, hal ini berarti laki-laki memiliki ketahanan yang lama terhadap rasa nyeri dibandingkan perempuan. Hasil penelitian yang sama juga dilakukan oleh Naharuddin (2013) yang menyimpulkan bahwa laki-laki memiliki durasi ambang rasa nyeri yang lebih lama dibandingkan perempuan. ${ }^{4}$ Hasil penelitian yang dikemukakan oleh Barkley pada tahun 1997 menyatakan bahwa wanita memiliki ambang nyeri yang rendah. ${ }^{5}$

Berdasarkan usia, peneliti membagi ke dalam 4 kelompok yaitu kelompok usia 17-25 tahun, 26-35 tahun, 36-45 tahun dan 46-55 tahun, dari hasil penelitian menunjukkan bahwa usia tidak memberi pengaruh terhadap durasi ambang nyeri. Penelitian yang dilakukan Effendy tahun 2014 juga menyatakan bahwa tidak ada perbedaan nyeri yang signifikan pada pasien dewasa dan pasien berusia tua. ${ }^{6}$
Berdasarkan keadaan gigi sebelum pencabutan pada penelitian yang telah dilakukan terdapat 2 diagnosis yaitu nekrosis pulpa dan pulpitis irreversibel. Pada penelitian didapatkan bahwa rata-rata durasi ambang nyeri pada pasien dengan diagnosis nekrosis pulpa lebih lama dibandingkan pada pasien dengan diagnosis pulpitis irreversible. Penelitian yang dilakukan oleh Naharuddin M pada tahun 2013 di dapatkan bahwa rata-rata durasi ambang rasa nyeri pada pasien dengan diagnosis nekrosis pulpa lebih lama daripada pasien yang datang dengan diagnosis pulpitis irreversible. ${ }^{4} \mathrm{Hal}$ ini disebabkan oleh perbedaan gejala dari kedua diagnosis tersebut, gejala berupa nyeri ini lebih mungkin dapat dirasakan oleh pasien dengan diagnosis pulpitis irreversibel disebabkan karena keadaan pulpa pada diagnosis tersebut belum nekrosis sehingga masih mungkin mengalami nyeri sedangkan pada diagnosis nekrosis pulpa, keadaan jaringan pulpa sudah mati sehingga memiliki kemungkinan kecil mengalami nyeri. ${ }^{4}$

Berdasarkan keadaan gigi tidak dapat dijadikan patokan pemicu lama tidaknya durasi ambang nyeri pada pasien, karena sebelum melakukan tindakan pencabutan gigi pasien dilakukan anestesi pehacaine. Anestesi yang diberikan pada pasien sebelum pencabutan gigi merupakan salah satu manajemen nyeri yang dilakukan oleh operator. Anestesi yang diberikan pada pasien yang tidak diberikan 
asam mefenamat 1 jam sebelum anestesi memiliki rata-rata durasi ambang nyeri 2 jam 11 menit sedangkan pasien yang diberi asam mefenamat 1 jam sebelum dilakukan anestesi memiliki rata-rata durasi ambang nyeri lebih lama 3 jam 28 menit; hal ini disebabkan oleh kerja obat asam mefenamat ikut menambah efek analgesik setelah pemberian anestesi terhadap durasi ambang nyeri pada pasien.

Berdasarkan pemberian analgesik sebelum pencabutan gigi didapatkan bahwa pasien yang diberi analgesik asam mefenamat sebelum pencabutan gigi memiliki durasi ambang nyeri yang lama dibandingkan dengan pasien yang tidak diberikan obat. Durasi ambang nyeri kelompok uji dan kelompok kontrol dengan selisih waktu 1 jam 17 menit lebih lama durasinya pada pasien yang diberikan asam mefenamat sebelum pencabutan gigi. Pada penelitian yang dilakukan Naharuddin M pada tahun 2013 yang mana pada penelitian tersebut memberikan analgesik jenis opioid yaitu tramadol sebelum pencabutan gigi dengan ratarata durasi 4 jam lebih lama dibandingkan dengan yang tidak diberikannya tramadol. ${ }^{4}$

\section{SIMPULAN}

Dari hasil penelitian dapat disimpulkan bahwa setelah pencabutan gigi, durasi ambang nyeri pada pasien yang diberikan asam mefenamat sebelum pencabutan gigi lebih lama dibandingkan dengan yang tidak diberikan asam mefenamat sebelum pencabutan gigi. Rata-rata durasi 3 jam 28 menit dan 2 jam 11 menit, jadi selisihnya 1 jam 17 menit.

\section{SARAN}

1. Perlu dilakukan penelitian lebih lanjut mengenai pemberian analgesik NSAID (non steroid anti inflammatory drug ) yang lain sebelum pencabutan gigi sebagai manajemen nyeri setelah pencabutan gigi.

2. Bagi mahasiswa kedokteran gigi khususnya mahasiswa klinik untuk lebih memerhatikan cara manajemen nyeri sebelum pencabutan gigi, khususnya pada kasus bedah minor seperti odontektomi.

\section{DAFTAR PUSTAKA}

1. Prasetyo EP. Peran musik sebagai fasilitas dalam praktek dokter gigi untuk mengurangi kecemasan pasien. Maj Ked Gigi (Dent J). 2005;38(1):41-4.

2. Markam S, Laksman H, Ganiswarna S. Kamus Kedokteran. Jakarta: Fakultas Kedokteran Universitas Indonesia, 2011; p. 202.

3. Gunawan SG, Setiabudy R, Nafrialdi, Elysabeth. Farmakologi dan terapi. Jakarta: Departemen Farmakologi dan Terapeutik Fakultas Kedokteran Universitas Indonesia, 2007; p. 21031.

4. Naharuddin M. Pengaruh pemberian premedikasi tramadol terhadap durasi ambang nyeri setelah pencabutan gigi [Skripsi]. Makassar: FKG Universitas Hasanuddin; 2013.

5. Barkley KJ. Sex in differences in pain. Behavioral and Brain Sciences. 1997; 20(3):371-80.

6. Effendy AH. Perbedaan efektifitas manajemen nyeri pasca ekstraksi gigi di RSUD dr. Soehadi Prijonegoro Sragen dan puskesmas Sidoharjo Sragen [Skripsi]. Semarang: FK Universitas Diponegoro; 2014. 